\title{
Best Macular Dystrophy in a Nigerian: A Case Report
}

\author{
Tunji S. Oluleye
}

Retinal and Vitreous Unit, Department of Ophthalmology, University College

Hospital, Ibadan, Nigeria

\section{Key Words}

Best macular dystrophy $\cdot$ Choroidal neovascular membrane $\cdot$ Retina $\cdot$ Nigerian

\begin{abstract}
Best macular dystrophy is reported to be rare in Africans. It is a hereditary disease that starts in childhood and progresses through some stages before visual symptoms occur. This case report presents a 43-year-old Nigerian with the disease and stresses the importance of regular eye exams of patients and relatives to detect changes such as choroidal neovascular membrane amenable to treatment.
\end{abstract}

\section{Case Presentation}

A.T., a 43-year-old Nigerian lady, presented to the Eye Clinic of the University College Hospital, Ibadan with gradual blurring of vision in both eyes for 4 years. Two of her siblings were reported to have similar complaints. Ocular examination showed unaided visual acuity of $6 / 12$ OU corrected to $6 / 9$ in both eyes. Near vision was normal. The anterior segment examination was not remarkable. IOP was $13 \mathrm{~mm} \mathrm{Hg}$ in both eyes. Dilated fundoscopy showed a well circumscribed cystic fovea lesion with a fluid level and an atrophic center in the right eye, while the left eye showed a scar in the macula (fig. 1 and fig. 2). The systemic examination was not remarkable. An assessment of Best macular dystrophy was made. The patient was prescribed with spectacles, counseled and placed on close observation with Amslers grid for the development of choroidal neovascular membrane that will require urgent treatment.

\section{Discussion}

This is probably the first case of Best macular dystrophy to be reported in Ibadan, Nigeria and possibly Sub-Saharan Africa to the best of the author's knowledge. The disease is a hereditary macular dystrophy first described by Best in 1905 [1]. It has also been reported in Caucasians and Asians [2], the other cases seen in African Americans were associated with sickle cell trait [3]. The disease starts in childhood with a 
characteristic macular lesion resembling an egg yolk. It progresses through some stages before visual symptoms become apparent. Table 1 describes these stages [4].

\section{Pathophysiology}

The pathophysiology of Best's disease is explained by abnormality in the retinal pigment epithelium (RPE) with resultant abnormal ionic transport leading to the accumulation of lipofuscin in the RPE cells and sub-RPE space in the macular area. Degeneration of RPE cells can occur [5, 6].

Vision is good in the early stages of the disease. The vitelliruptive stage may herald visual deterioration which becomes worse in the atrophic stage due to the presence of choroidal neovascular membrane. Our patient presented with the early stages of the disease, hence the good visual acuity. The patient will be under observation and followup so as to detect changes amenable to treatment. Choroidal neovascular membrane (CNVM) from Best's disease has been reported to respond well to intravitreal antiVEGF $[7,8]$. Fundus flourescein angiography is essential in confirming the presence of CNVM and should be done when patient presents with sudden deterioration in vision. If a CNVM develops, then a corresponding area of hyperfluorescence with leakage will be found.

Since the disease is an autosomal dominant disorder, other family members will benefit from regular fundus examinations, and Amslers grid is a valuable tool for monitoring central vision. An electrophysiologic test such as electrooculogram (EOG) is specific for confirming the presence of the disease in relatives even in the absence of clinical signs and symptoms. A severe decrease occurs in light response, reflected by an Arden (light-peak/dark-trough) ratio of 1.1-1.5 (the normal Arden ratio is 1.8) [9]. The full-field electroretinogram (ERG) result is normal in Best's disease. A focal ERG or multifocal ERG, concentrating on macular function, reveals abnormal function corresponding to the area of anatomical disruption [10].

\section{Conclusion}

This is a report of Best macular dystrophy in Ibadan, Sub-Saharan Africa. Regular eye exams are advised for families with the disease. Other so-called rare ocular diseases may not be so after all. 
Table 1. Stages of Best macular dystrophy (modified) [4]

\begin{tabular}{llll}
\hline Stage of disease & Findings & Expected visual acuity \\
\hline I & Pre-vitelliform & Speckled fine pigmentary disturbance in the macula is seen & $6 / 6$ \\
\hline II & Vitelliform & $\begin{array}{l}\text { Egg-yolk lesion composed of a round, homogeneous, } \\
\text { opaque yellow lesion with discrete margins measuring } \\
\text { approximately 1 disc diameter in size }\end{array}$ & $6 / 6-6 / 12$ \\
\hline III & $\begin{array}{l}\text { Pseudo- } \\
\text { hypopyon }\end{array}$ & $\begin{array}{l}\text { The yellow material within the vitelliform cyst develops a } \\
\text { fluid level, resulting in the appearance of a pseudohypopyon }\end{array}$ & $6 / 6-6 / 36$ \\
\hline IV & $\begin{array}{l}\text { Vitelliruptive } \\
\text { atrophic }\end{array}$ & $\begin{array}{l}\text { Advanced disease with an atrophic macular pigment } \\
\text { epithelium (stage IVa), fibrous scarring (stage IVb), or } \\
\text { subretinal neovascularization (stage IVc) }\end{array}$ & $\begin{array}{l}\text { 6/6-6/60, CNVM may } \\
\text { be associated with VA } \\
\text { less than 6/60 }\end{array}$ \\
\hline
\end{tabular}

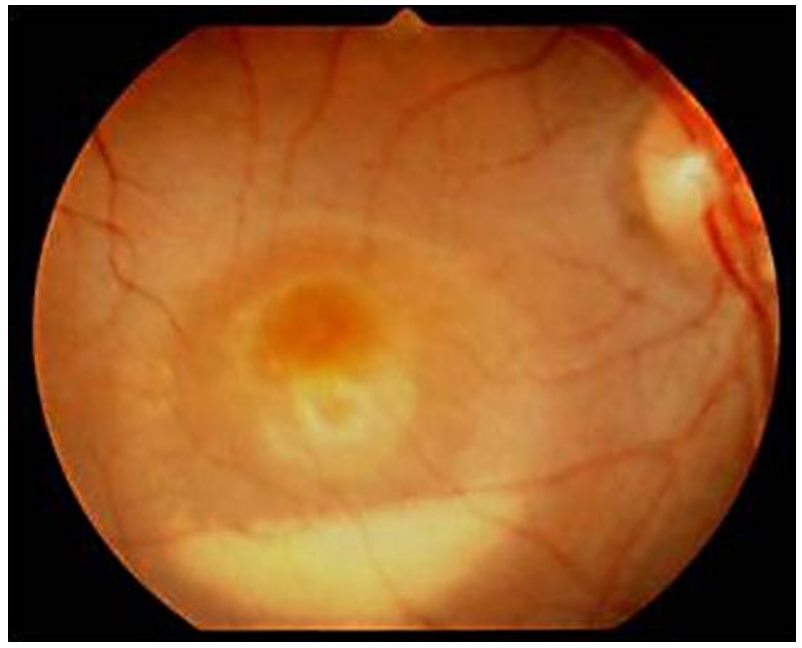

Fig. 1. Right eye of patient with the pseudohypopyon stage of Best's disease. 


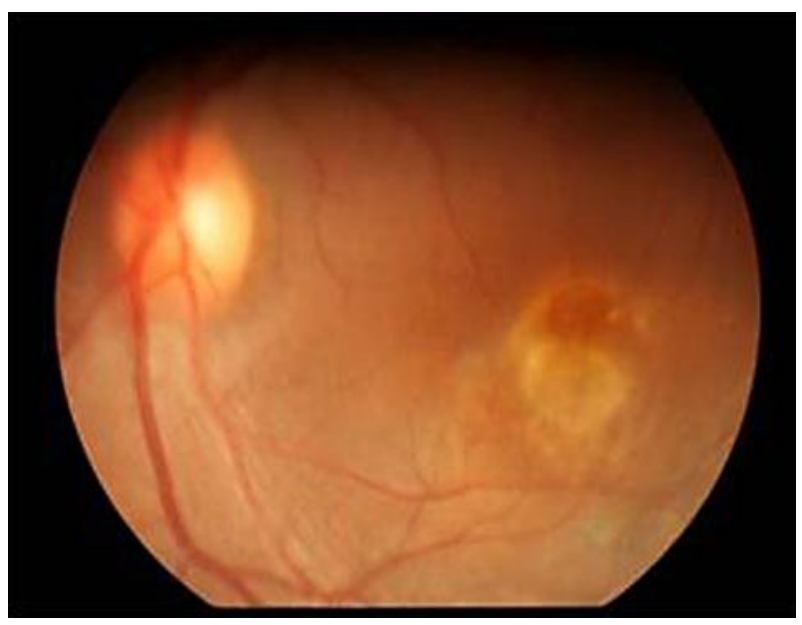

Fig. 2. Left eye of patient with the atrophic stage of Best's disease.

\section{References}

1 Best F: Über eine hereditäre Maculaaffektion. Beitrag zur Vererbungslehre. Augenheilkd 1905;13:199_ 212.

-2 Shibuya Y, Hayasaka S: Various fundus manifestations in a Japanese family with Best's vitelliform macular dystrophy. Jpn J Ophthalmol 1993;37:478.

-3 Galinos SO, Birrer RB, Tsamparlakis J, et al: Multifocal Best's disease and sickle cell trait. Ann Opthalmol $1981 ; 13: 1181$

4 Mohler CW, Fine SL: Long-term evaluation of patients with Best's vitelliform dystrophy. Ophthalmology 1981;88:688.

5 Hartzell HC, Qu Z, Yu K, Xiao Q, Chien LT: Molecular physiology of bestrophins: multifunctional membrane proteins linked to best disease and other retinopathies. Physiol Rev Apr 2008;88:639-672.

6 Weingeist TA, Kobrin JL, Watzke RC: Histopathology of Best's macular dystrophy. Arch Ophthalmol Jul 1982;100:1108-1114.

-7 Iannaccone A, Kerr NC, Kinnick TR, Calzada JI, Stone EM: Autosomal recessive Best vitelliform macular dystrophy: report of a family and management of early-onset neovascular complications. Arch Ophthalmol 2011;129:211-217.

-8 Ekta R, Pukhraj R, Sheshadri M: Intravitreal bevacizumab for choroidal neovascular membrane associated with Best's vitelliform dystrophy. Indian J Ophthalmol 2010;58:160-162.

$>9$ Deutman AF: Electro-oculography in families with vitelliform dystrophy of the fovea. Detection of the carrier state. Arch Ophthalmol Mar 1969;81:305-316.

10 Glybina IV, Frank RN: Localization of multifocal electroretinogram abnormalities to the lesion site: findings in a family with Best disease. Arch Ophthalmol Nov 2006;124:1593-1600. 